\title{
Case Report on Saphenous Vein Graft Aneurysm with Fistula Development
}

\section{to The Right Atrium}

\section{Rohan Madhu Prasad ${ }^{1 *}$ | Zulfiqar Qutrio Baloch ${ }^{2}$ | Shabber Agha Abbas ${ }^{3}$ | Mohammad Fahad Salam $^{1}$ | Abdullah Al-abcha ${ }^{1}$ | William Bugni ${ }^{4}$}

*Correspondence: Rohan Madhu Prasad

Address: ${ }^{1}$ Department of Internal Medicine, Michigan State University - Sparrow Hospital, MI; ${ }^{2}$ Sparrow Thoracic and

Cardiovascular Institute - Sparrow Hospital, MI; ${ }^{3}$ Internal Medicine, R-endocrinology, NJ; ${ }^{4}$ Bay Area Cardiology, Brandon Regional Hospital, FL

e-mail $\bowtie$ : rohanmaprasad@gmail.com

Received: 16 December 2021; Accepted: 21 December 2021

Copyright: (C) 2021 Madhu Prasad R. This is an open-access article distributed under the terms of the Creative Commons Attribution License, which permits unrestricted use, distribution, and reproduction in any medium, provided that the original work is properly cited.

\section{ABSTRACT}

Saphenous vein graft aneurysms (SVGA) are rare complications after coronary artery bypass graft (CABG) operation, which can develop fatal complications including cardiac ischemia, compression, rupture, and death. A 72-year-old male patient presented four years post-CABG with dyspnea. Investigations showed a saphenous vein graft aneurysm with fistulization to the right atrium. During the catheterization, the large coronary artery graft aneurysm was seen on the right measuring up to 6.0 x $4.7 \times 6.7$ centimeters. This was successfully operated by surgical excision and repaired. The patient was eventually discharged home. Commonly SVGAs are asymptomatic, but clinically significant ones are possible and should be diagnosed and treated appropriately. Keywords: Saphenous Vein Graft Aneurysm, Fistula, Right Atrium, Coronary Artery Bypass Graft

\section{Introduction}

Aneurysms are organized into categories of true versus false and early versus late (Ramirez et al., 2012). While mild saphenous vein graft aneurysms (SVGA) are common, clinically significant SVGAs are rare with complicated forms presenting as myocardial infarction and fistula formation to adjacent structures (Khan et al., 2019; Gruberg et al., 1999; Kim et al., 1983; Memon et al., 2003; Benchimol et al., 1975). Diagnosis can be confirmed by coronary angiography or computed tomography coronary angiogram with contrast (Khan et al., 2019; Memon et al., 2003). The options for treatment of SVGAs include medical management, percutaneous interventions, and surgical repair (Ramirez et al., 2012; Khan et al., 2019). 


\section{Case Presentation}

A 72-year-old male with a history of congestive heart failure, hypertension, hypercholesterolemia, and peripheral arterial disease presented with progressive dyspnea six years after coronary artery bypass graft (CABG) for severe left mainstem arterial stenosis. Cardiac examination found normal S1 and S2 heart sounds with no murmurs, gallops, or rubs. A chest radiograph showed dilated heart, mild pulmonary vascular congestion, and right-sided pleural effusion. Computed tomography (CT) scan of the chest revealed a $6.0 \times 4.7 \times 6.7$-centimeter ball-like mass compressing the right atrium (Fig. 1) and fistulization to the right atrium (Fig. 2). An echocardiogram showed a moderately reduced systolic function with an ejection fraction of 30-35\%. Catheterization from the aorta to the RCA redemonstrated the large SVGA that emptied into the right atrium and RCA.

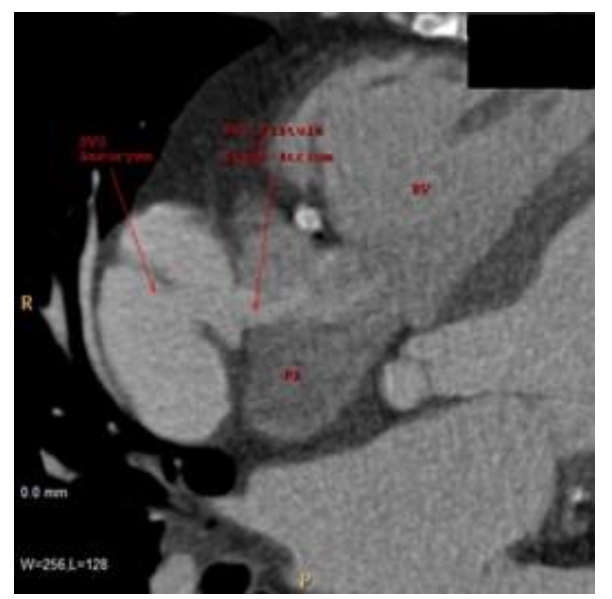

Figure 1: Computed tomography of coronary angiography showing saphenous vein graft aneurysm $(6.0$ x 4.7 x $6.7 \mathrm{~cm})$ and fistula to the right atrium and right coronary artery.

Coronary angiography and urgent open-heart surgery were performed and redemonstrated fistulization of the SVGA to the right atrium (Fig. 2). Cardiopulmonary bypass was instituted between the left femoral artery and vein before re-sternotomy. Antegrade cold blood cardioplegic solution was instilled into the aortic root during aortic cross-clamping to provide myocardial protection. Cardiac surgery was performed to excise the aneurysm, repair the fistula with a bovine pericardial patch, and revascularize the RCA. The SVGA part of the RCA was transected and repaired with buttressed sutures. Thereafter, the patient was weaned from cardiopulmonary bypass without any complications. A CT coronary angiogram with contrast was performed two days later and confirmed occlusion of the aneurysm. A repeat echocardiogram showed a normal ejection fraction. The patient was discharged to his skilled nursing home. He came to a routine four-week follow-up appointment where he denied any acute symptoms, including recurrent or current chest pain, and no modifications were made to his medication regimen. 


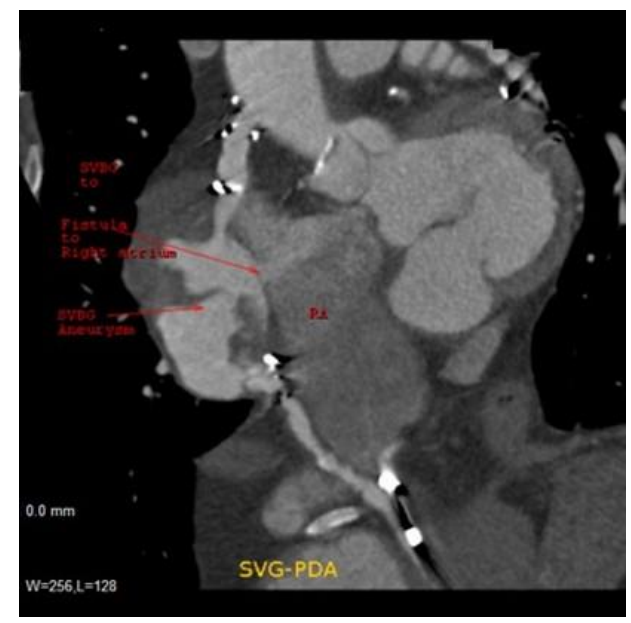

Figure 2: Computed tomography of coronary angiography showing fistulization of saphenous vein graft aneurysm to the right atrium.

\section{Discussion}

Aneurysms are defined as abnormal vessel dilation that is 1.5 times greater than the proximal reference value (Ramirez et al., 2012). They can be classified into true and false, also known as pseudoaneurysms. True aneurysms are characterized by the expansion of all cell layers of the wall and are lined by endothelium. Pseudoaneurysms are the expansion of one or more cell layers (but not all), not lined by endothelium, and represent focal distension with a hematoma (Stedman, 1995). Based on their timing of development, they can also be categorized as early and late aneurysms. Early aneurysms present less than 12 months after surgery and are most likely pseudoaneurysms. Early aneurysms are typically caused by technical failures during conduit harvesting, preparation, and grafting (Kallis et al., 1993; Werthman et al., 1991). Other rare associations include infection of the implanted graft, intrinsic weakness of the graft vessel (such as from undetected varicosities), and anastomotic suture disruption (Douglas et al., 1979; Ennis et al., 1993; de Haan et al., 1995). Late aneurysm forms after greater than five years from the initial $C A B G$, are more often true aneurysm, and arise due to an ongoing atherosclerotic process (Ramirez et al., 2012). Specific pathophysiological reasons for true SVGAs include hyperlipidemia, atherosclerosis, and graft wall weakness near the valve sites (Benchimol et al., 1915; Liang et al., 1988; Teja et al., 1987; Neitzel et al., 1986).

Six years after his surgery, our patient developed progressive symptoms and imaging findings were consistent with a true, late SVGA. A successful CABG was performed using a saphenous vein to revascularize the RCA and bypass the affected vessel. There was no history of varicosities or other vascular insufficiencies that would decrease the quality of the graft. Proximal and distal ends were sealed using continuous sutures of propylene monofilaments. 
Although mild SVGAs are very common, with an incidence of approximately $14 \%$ within five to seven years after CABGs, clinically significant SVGAs are rare (Khan et al., 2019; Gruberg et al., 1999; Kim et al., 1983). Pseudoaneurysms of a saphenous vein graft is more frequently symptomatic with recurrent chest pain a common presentation. They can also present with infection, hemopericardium, hemothorax, hemoptysis, and sudden cardiac death (Memon et al., 2003). Cases have reported fistula development from an SVGA that involves adjacent structures such as the superior vena cava, atria, right ventricle, pulmonary artery, and even the chest wall. Benign progression is a feature associated with true SVGA (Memon et al., 2003). Overall, the presentation of aneurysms is highly variable. Most of them are asymptomatic and are discovered incidentally as a mediastinal mass on chest x-ray or on CT scan that was performed for other reasons. Additionally, patients with uncomplicated symptomatic SVGAs can present for anginal symptoms or superior vena cava syndrome. On the other hand, complicated symptomatic SVGAs can be acutely present with myocardial infarction or fistula formation. Coronary angiography is the diagnostic modality to confirm aneurysmal dilation, but sometimes it cannot provide the dimensions of an aneurysm due to a thrombus formation at the site (Benchimol et al., 1975). In these cases, CT coronary angiogram with contrast can be helpful. Therefore, the final treatment plan should be based on the findings of both the angiogram and CT scan (Benchimol et al., 1975). Magnetic resonance angiography is another diagnostic modality that is useful in evaluating SVGAs (Benchimol et al., 1975).

Treatment of SVGAs focuses on preventing complications and repairing the graft. The options include medical management with surveillance, percutaneous intervention, or surgical repair. Medical therapy is favored in patients with a low risk of rupture, aneurysm diameter less than one centimeter, or brisk flow through the graft. In poor surgical candidates, percutaneous interventions are considered and include covered stent grafting (Bhindi et al., 2009; Rahim et al., 2009), coil embolization (Maroo et al., 2006), vascular plug insertion (Mylonas et al., 2006), or alcohol injection into the graft (Mylonas et al., 2006). Finally, surgical options include excision, fistula repair, and re-grafting (Sonnenberg et al., 2010).

Although clinically significant SVGAs are rare, if they become complicated the patients can present with myocardial infarctions or fistualizations. Physicians should have a high clinical suspicion for these and consider coronary angiography to confirm the diagnosis. Moreover, CT coronary angiogram with contrast is the gold standard method of treatment.

\section{References}

Benchimol A, Harris CL, Desser KB, Fleming H. Aneurysms of an aorto-coronary artery saphenous vein bypass graft--a case report. Vasc Surg 1975; 9: 261-264.

Bhindi R, Newton J, Westaby S, Wilson N, Ormerod OJ, Uberoi R. Stent-graft repair of coronary vein graft aneurysm. J Vasc Interv Radiol 2009; 20: 649-651. 
de Haan HP, Huysmans HA, Weeda HW, Bosker HA, Buis B. Anastomotic pseudoaneurysm after aorto-coronary bypass grafting. Thorac Cardiovasc Surg 1985; 33: 55-56.

Douglas BP, Bulkley BH, Hutchins GM. Infected saphenous vein coronary artery bypass graft with mycotic aneurysm. Fatal dehiscence of the proximal anastomosis. Chest 1979; 75: 76-77.

Ennis BM, Zientek DM, Ruggie NT, Billhardt RA, Klein LW. Characterization of a saphenous vein graft aneurysm by intravascular ultrasound and computerized three-dimensional reconstruction. Cathet Cardiovasc Diagn 1993; 28: 328-331.

Gruberg L, Satler LF, Pfister AJ, Monsein LH, Leon MB. A large coronary artery saphenous vein bypass graft aneurysm with a fistula: case report and review of the literature. Catheter Cardiovasc Interv 1999; 48: 214-216.

Kallis P, Keogh BE, Davies MJ. Pseudoaneurysm of aortocoronary vein graft secondary to late venous rupture: case report and literature review. Br Heart J 1993; 70: 189-192.

Khan A, Med SBB, Boyle A, Collins N. Percutaneous treatment of saphenous vein graft aneurysm: Contemporary procedural considerations. Catheter Cardiovasc Interv 2019; 93: 927-932.

Kim D, Guthaner D, Wexler L. Transcatheter embolization of a leaking pseudoaneurysm of saphenous vein aortocoronary bypass graft. Cathet Cardiovasc Diagn 1983; 9: 591-594.

Liang BT, Antman EM, Taus R, Collins Jr JJ, Schoen FJ. Atherosclerotic aneurysm of aortocoronary vein grafts. Am J Cardiol 1988; 61: 185-188.

Maroo A, Rasmussen PA, Masaryk TJ, Ellis SG, Lincoff AM, Kapadia S. Stent-assisted detachable coil embolization of pseudoaneurysms in the coronary circulation. Catheter Cardiovasc Interv 2006; 68: 409-415.

Memon AQ, Huang RI, Marcus F, Xavier L, Alpert J. Saphenous vein graft aneurysm: case report and review. Cardiol Rev 2003; 11: 26-34.

Mylonas I, Sakata Y, Salinger MH, Feldman T. Successful closure of a giant true saphenous vein graft aneurysm using the Amplatzer vascular plug. Catheter Cardiovasc Interv 2006; 67: 611-616.

Neitzel GF, Barboriak JJ, Pintar K, Qureshi I. Atherosclerosis in aortocoronary bypass grafts. Morphologic study and risk factor analysis 6 to 12 yrs after surgery. Arteriosclerosis 1986; 6: 594-600.

Rahim SA, Pitta SR, Rihal CS. Saphenous vein graft pseudoaneurysm. J Am Coll Cardiol 2009; 53: 1918.

Ramirez FD, Hibbert B, Simard T, Pourdjabbar A, Wilson KR, Hibbert R, Kazmi M, Hawken S, Ruel M, Labinaz M, O'Brien ER. Natural history and management of aortocoronary saphenous vein graft aneurysms: a systematic review of published cases. Circulation 2012; 126: 2248-2256.

Sonnenberg B, Rutledge J, Welsh RC. Occlusion of a large expanding saphenous vein bypass graft aneurysm with percutaneously injected ethylene-vinyl alcohol copolymer. JACC Cardiovasc Interv 2010; 3: 1089-1090.

Stedman TL. Stedman's medical dictionary. 26th ed. Philadelphia, PA: Williams \& Wilkins 1995: 1450.

Teja K, Dillingham R, Mentzer RM. Saphenous vein aneu- rysms after aortocoronary bypass grafting: postoperative interval and hyperlipidemia as determining factors. Am Heart J 1987; 113: 1527-1529.

Werthman PE, Sutter FP, Flicker S, Goldman SM. Spontaneous, late rupture of an aortocoronary saphenous vein graft. Ann Thorac Surg 1991; 51: 664-666. 